\title{
To Make Good Decision: A Group DSS for Multiple Criteria Alternative Rank and Selection
}

\author{
Chen-Shu Wang, ${ }^{1}$ Heng-Li Yang, ${ }^{2}$ and Shiang-Lin Lin ${ }^{2}$ \\ ${ }^{1}$ Graduate Institute of Information Management, National Taipei University of Technology, Taiwan
}

${ }^{2}$ Department of Management Information Systems, National Chengchi University, Taiwan

Correspondence should be addressed to Shiang-Lin Lin; shiang0623@gmail.com

Received 26 September 2014; Accepted 7 January 2015

Academic Editor: Jianming Shi

Copyright (C) 2015 Chen-Shu Wang et al. This is an open access article distributed under the Creative Commons Attribution License, which permits unrestricted use, distribution, and reproduction in any medium, provided the original work is properly cited.

Decision making is a recursive process and usually involves multiple decision criteria. However, such multiple criteria decision making may have a problem in which partial decision criteria may conflict with each other. An information technology, such as the decision support system (DSS) and group DSS (GDSS), emerges to assist decision maker for decision-making process. Both the DSS and GDSS should integrate with a symmetrical approach to assist decision maker to take all decision criteria into consideration simultaneously. This study proposes a GDSS architecture named hybrid decision-making support model (HDMSM) and integrated four decision approaches (Delphi, DEMATEL, ANP, and MDS) to help decision maker to rank and select appropriate alternatives. The HDMSM consists of five steps, namely, criteria identification, criteria correlation calculation, criteria evaluation, critical criteria selection, and alternative rank and comparison. Finally, to validate the proposed feasibility of the proposed model, this study also conducts a case study to find out the important indexes of corporate social responsibility (CSR) from multiple perspectives. As the case study demonstrates the proposed HDMSM enables a group of decision makers to implement the MCDM effectively and help them to analyze the relation and degree of mutual influence among different evaluation factors.

\section{Introduction}

People are making decision all the time. Typically, decision making is a recursive process in which decision maker may repeatedly move back and forth among multiple decision steps, such as objective clarification, decision criteria identification, alternative rank, and selection. For decision maker, the primary concern is to pick up an appropriate choice from a group of candidate alternatives [1]. Such decision making process usually involves multiple decision criteria [2], so called as multiple criteria decision making (MCDM) [3]. Lots of researches are devoted to resolve sorts of MCDM problem. For example, Hung et al. provide a novel MCDM approach to solve the knowledge management (KM) adoption problem and rank the gaps of the KM aspects in control items to achieve the aspired level of performance. The findings demonstrate that the KM gaps within the service industry are higher than the gaps within the integrated circuit and banking industries [4]. Also, Hsu et al. combine DEMATEL on ANP with VIKOR to solve the recycled materials vendor selection problems of multiple dimensions and criteria that are interdependent, instead of the independent assumption of an analytic hierarchy process, for mimicking the real world [5]. Besides, Chiu et al. focus on assessing e-store strategies to reduce the gaps in the resulting customer satisfaction and combine several multicriteria decision methodologies to conduct three real cases [6]. As mentioned above, MCDM is a complicated problem but can reflect real world precisely and therefore we should pay more attention to resolve MCDM issue.

However, unfortunately, most people are much poorer at decision making than they think. For illustration, there is a misconception that the decision maker thought they do not have enough information to make good decision [7]. Contrarily, in most cases, they spend much time to collect relative (or even irrelevant) information and trap themselves 
in the huge amount of information. Decision making is a sophisticated art and decision makers indeed require some help.

An information technology, as known as decision support system (DSS), emerges to assist decision maker to accelerate the convergence of decision-making process. DSS is interactive computer-based information system which helps decision-makers utilize knowledge base and models to solve ill-structured problems [8]. For these decades, DSS has been widely applied among domains as follows. Koo et al. developed a DSS based on case-based reasoning approach for determining the optimal size of new expressway service areas [9]. Gottschlich and Hinz proposed a DSS design that enables investors to include the crowd's recommendations in their investment decisions and use it to manage a portfolio [10]. Hu and Sheng also proposed a DSS for public logistics information service management and optimization for vehicle drivers and owners, logistics customers, and related logistics service providers and management institutes [11]. Then, to respond accordingly to the requirement of group decision making, DSS further evolves into group DSS (GDSS) to help group of decision makers with efficiency decision making [12-16]. A group decision support system (GDSS) is a hybrid system that uses an elaborate communications infrastructure and quantitative models to help a team of decision makers solve problems and make choices $[17,18]$. However, the decision process is a classical multiple criteria problem that partial decision criteria may conflict with each other. Both the DSS and GDSS should integrate with a symmetrical approach to assist decision maker to take all decision criteria into consideration simultaneously.

In this research, we proposed a hybrid GDSS architecture, named HDMSM, integrated four decision approaches (Delphi, DEMATEL, ANP, and MDS) to help decision maker with alternative rank and selection issue. HDMSM consists of four steps. In Step 1, HDMSM adopts Delphi to collect the decision criteria from domain experts. After that, in Step 2, domain experts use DEMATEL approach to evaluate the relevant among the selected criteria (in Step 1) and then generate a correlation matrix of these decision criteria. Then, in Step 3, HDMSM adopts ANP to calculate the correlation and important weight for each decision criteria in Step 4. Finally, in Step 5, the MDS can rank all available alternatives according to these important weights and visualize the similarity (or difference) of all available alternatives.

The priorities of decision criteria imply the preference of domain expert and therefore, to make better decision, and decision maker can make their choice according to the alternative rank via HDMSM. Also, the visual abilities of HDMSM enable decision maker to compare all available alternative form perspective and then improve decision making quality. Finally, we provide a system demonstration section to illustrate that how HDMSM aggregated the opinion from a group of domain experts. How to appropriately integrate a variety of MCDM approaches is an important issue in decision science [19]. HDMSM provides a valuable recommendation for decision maker to optimize multiple criteria decision making.
The remainder of this paper is organized as follows. Section 2 briefly reviews four decision analysis methodologies adopted in this study. Section 3 presents the proposed hybrid decision-making support model (HDMSM) and details the operational process of HDMSM. To validate the feasibility of HDMSM, according to five steps of HDMSM, a case study in Section 4 illustrates how decision makers appropriately select multiple decision criteria for corporate social responsibility (CSR) implementation step by step. Finally, Section 5 concludes some interest finding and proposes possible future research opportunities.

\section{Literature Review}

The HDMSM proposed in this study integrates four decision approaches, namely, Delphi, DEMATEL, ANP, and MDS, to help decision maker with criteria selection and alternative ranking when facing a decision problem. Four methodologies are briefly introduced below.

2.1. Delphi Method. Delphi method relies mainly on a panel of experts' experiences, intuition, and value judgment. The experts participate in multiple rounds of questionnaire interviews and are given ways to understand one another's viewpoints on the same question. The experts are encouraged to revise their previous opinions, so that the experts as a group can finally reach a consensus on the goal of decision making [19]. To perform the Delphi method, the following procedures are included.

2.1.1. Choose a Panel of Decision-Making Experts and Select the Criteria for Decision Making. Determine the goal of decision making and list relevant evaluation criteria for the decision making, choose experts in the related field to form an expert group, and invite the experts to answer in a Delphi expert questionnaire interview for multiple rounds. The experts must judge the importance and suitableness for each evaluation criteria and give each criterion a score between 0 and 100 .

2.1.2. Test the Expert Group Consensus. To enable expert group to gradually reach a general agreement of opinion, a consensus deviation index (CDI) for each evaluation criteria is calculated as a round of the Delphi expert questionnaire finished. A smaller CDI indicates a higher consensus among the experts. In general, a CDI threshold is set to 0.05 . That is, when the last round of Delphi expert questionnaire is completed and the CDI for all of the evaluation criteria is smaller than 0.05 , this indicates a consensus of experts has been reached [20]. Herein, the score of the $j$ th criterion rated by the $h$ th expert in the $t$ th round of Delphi questionnaire is defined as $X_{j h t}$, and the CDI is calculated by the formula:

$$
\mathrm{CDI}_{j t}=\frac{S_{j t}}{\max _{j} \bar{X}_{j t}}, \quad \forall j, t,
$$

where $\overline{\bar{X}}_{j t}$ is the mean of the scores of the $j$ th criterion rated by all the experts in the $t$ th round of Delphi expert 
questionnaire, and $S_{j t}$ is the standard deviation of the scores of the $j$ th evaluation criterion rated by all the experts in the $t$ th round of Delphi expert questionnaire.

\subsubsection{Normalize the CDI and Choose the Evaluation Criteria.} The CDI calculated based on the last round of Delphi expert questionnaire has to be normalized to derive the relative weight $W_{j}$ of each of the evaluation criteria. A small weight indicates the criterion does not have sufficient influence on the decision problem. In other words, when the weight of a particular criterion is less than a threshold set by the decision maker, the criterion is deleted from the candidate decision criteria, wherein $W_{j}$ is calculated by the following formula:

$$
W_{j}=\frac{\bar{X}_{j}}{\sum_{j=1}^{M} \bar{X}_{j}}, \quad \forall j
$$

The evaluation criteria involved in decision making problem can be identified via Delphi. Then, DEMATEL is adopted to analyze the direct/indirect effects among these evaluation criteria detailed below.

2.2. Decision-Making Trial and Evaluation Laboratory. Decision making trial and evaluation laboratory (DEMATEL) was originated from the Geneva of the Battelle Memorial Institute in 1973. It effectively observes the level of mutual influence among different factors and understands the complicated cause-and-effect relationship in the decision problem [21]. The analytic processes are listed below.

2.2.1. Define the Correlation among Evaluation Factors. List the factors that may affect the decision-making problem through literature review or brainstorming and interview with the domain experts to determine the correlation between any two factors.

2.2.2. Establish Direct Relation Matrix. As the decision problem has $n$ evaluated factors, an $n * n$ direct relation matrix showing the scores of influencing degree is established, which is presented as Z-matrix in formula (3). Element $z_{i j}$ represents the degree by which the factor $z_{i}$ affects factor $z_{j}$ :

$$
Z=\begin{gathered}
C_{1} \\
C_{2} \\
C_{1} \\
\vdots \\
C_{n}
\end{gathered}\left[\begin{array}{cccc}
0 & z_{12} & \cdots & z_{1 n} \\
z_{21} & 0 & \cdots & z_{2 n} \\
\vdots & \vdots & \ddots & \vdots \\
z_{n 1} & z_{n 2} & \cdots & 0
\end{array}\right] .
$$

2.2.3. Establish Direct/Indirect Relation Matrix. In order to understand whether two evaluation criteria relate to each other indirectly, formula (4) produces a direct/indirect relation matrix $T$, where $I$ is the identity matrix:

$$
T=\left|X(I-X)^{-1}\right|
$$

2.2.4. Calculate the Prominence Score. If $t_{i j}$ is an element of matrix $T$, where $i, j=1,2, \ldots, n$, the sum of the column and the row are denoted by $D_{i}$ and $R_{j}$, respectively. Among them, $D_{i}$ represents the sum of the criterion $i$ influencing other criteria, $R_{j}$ represents the sum of the criterion $j$ being affected by other criteria, and $D+R$ represents the prominence degree of each criterion in the decision-making problem. A prominence score can reveal both the importance and mutual effects among these criteria. In other words, DEMATEL analyzes the direct and indirect effect of these evaluation criteria on decision problem. The analysis results can be further plotted as a network structure via ANP approach.

2.3. Analytic Network Process. ANP is a decision-making analytical method that uses network and nonlinear structure to represent a decision problem. ANP is developed in response to the fact that many decision problems in the realistic environment could not be presented with the structured hierarchy. The main objective of ANP is to correct the traditional AHP, with which the problems of dependence and feedback might occur between the criteria or the layers [22].

ANP can decompose a decision problem into multiple types of dimensions, and each dimension can include multiple criteria. The dimensions and the criteria are correlated with one another to form a network structure of the evaluation framework, and arrows are used to indicate their mutual influence.

Through the pairwise comparison of among each two criteria, ANP is calculated to acquire the eigenvectors of criteria and to form a Supermatrix, as shown in

$$
W=\left[\begin{array}{cccc}
W_{i_{1} j_{1}} & W_{i_{1} j_{2}} & \cdots & W_{i_{1} j_{n}} \\
W_{i_{2} j_{1}} & W_{i_{2} j_{2}} & \cdots & W_{i_{2} j_{n}} \\
\vdots & \vdots & \ddots & \vdots \\
W_{i_{m} j_{1}} & W_{i_{m} j_{2}} & \cdots & W_{i_{m} j_{n}}
\end{array}\right] .
$$

Through normalization of the Supermatrix and complex matrix multiplication, a limit supermatrix containing the weights of the evaluation criteria can be obtained. According to these weights, the decision maker can figure out the priority of evaluation criterion for decision problem solving.

2.4. Multidimensional Scaling. Multidimensional scaling (MDS) is a data reduction method, which uses the distance or similarity between data points to locate the spatial coordinates and the relative positions of several given data in the low-dimensional space [23].

MDS computes the Euclidean distance between each two factors and shows all factors in perceptual map which has two dimensions. If the similarity between two factors is more stronger, the configuration of two factors would be more close in the map. As a result, through the illustration of perceptual map, the spatial relation among factors can be visualized more clearly. The classification results of factors can be achieved via spatial difference analysis that helps decision maker to easily grasp the concept of factors. 
To obtain the perceptual map, the Euclidean distance $\left(D_{i j}\right)$ between each two factors should be computed first. Further, the Euclidean distance matrix of the factors is generated. The Euclidean distance equation is shown as

$$
D_{i j}=\sqrt{\left(x_{i 1}-x_{j 1}\right)^{2}+\left(x_{i 2}-x_{j 2}\right)^{2}+\cdots+\left(x_{i k}-x_{j k}\right)^{2}},
$$

where $x_{i}$ denotes the perceived value of factor $a$ and $x_{j}$ denotes the coordinate of factor $b$.

For decision making, decision maker must locate important decision criteria and evaluate the fitness of all possible alternatives. To increase decision process, decision maker needs to compare these alternatives as soon as possible. Via MDS, the visualization of candidate alternative enables decision maker to quickly grasp the similarities and dissimilarities among the alternatives.

\section{Hybrid Decision-Making Support Model (HDMSM)}

This study proposes a GDSS architecture named hybrid decision-making support model (HDMSM) as shown in Figure 1. According to the decision-making procedures, HDMSM consists of five steps, namely, criteria identification, criteria correlation calculation, criteria evaluation, critical criteria selection, and alternative rank and comparison, which are detailed below.

Step 1 (criteria identification). To make MCDM, some appropriate evaluation dimensions and criteria are selected as candidate decision criteria. Then, a domain expert group is organized via Delphi for conducting multiple rounds of questionnaire interviews. To finally establish a consensus score for each of the criteria, the experts group gradually reaches a consensus in their opinions. Based on the consensus scores, the top $n$ decision criteria that with the highest important weight are chosen from the candidate criteria as evaluation criteria. Finally, these decision criteria are, respectively, given a detailed definition according to the opinions from the interviewed expert group.

Step 2 (criteria correlation calculation). To understand the correlation among the selected evaluation criteria in Step 1, it is necessary to further create a correlation matrix. According to the prominence of these criteria, for each criterion, DEMATEL evaluates the correlation among these criteria and calculates the prominence score.

Step 3 (criteria evaluation). To show the direct relation among these evaluation criteria, HDMSM plots a network structure of the evaluation framework. And then, an ANP expert questionnaire is designed based on the plotted evaluation framework. The domain experts fulfilled the ANP questionnaire and the collected questionnaires are further analyzed via ANP method to derive the absolute weight. Thereafter, for each decision criterion, it cross-multiplies the absolute weight by the consensus score (in Step 1) and the prominence score (in Step 2), to obtain a composite important weight. Finally, according to the composite importance weights, HDMSM can rank the decision criteria for MCDM.

Step 4 (critical criteria selection). To evaluate the feasibility for each alternative, multiple decision criteria are usually taken into consideration simultaneously. Therefore, in this step, according to the analysis results in Step 3, a decision maker sets a threshold for the composite important weight. If the evaluation criteria with a higher composite important weight, decision maker can pick them out and conduct pairwise comparison with alternatives to find out the priority of each alternative.

Step 5 (alternative rank and comparison). For particular complex case, appropriate alternative might be a combination of several alternatives. Therefore, the decision maker must understand the effect of each of the evaluation criteria. Additionally, they need to analyze the structural similarity among different alternatives. Therefore, in Step 5, MDS analysis is used to analyze the results from Step 4 for allocating the positions of the alternatives in a perceptual map of second dimension, so as to present the similarity and dissimilarity among the alternatives through visualization.

HDMSM adopts four methodologies that complement each other. Delphi summarizes the opinion from expert group and then generates appropriate evaluation factors for a multicriteria decision making. DEMATEL reveals the correlation among these decision factors. ANP implements pairwise comparison of these factors and derives the important weights for all evaluation factors. By importance ranking, ANP provides decision maker with the insight into the decision problem. Based on the analysis results, MDS generates the perceptual map to improve the representation of alternative analysis. The visualization representation enables decision maker to quick-grasp the similarity and dissimilarity among alternatives and increase decision making process.

\section{Case Study: To Select the Evaluation Factors of Corporate Social Responsibility}

A case study is implemented based on the proposed HDMSM. In this case study, we intend to find out the important indexes of corporate social responsibility (CSR) from multiple perspectives. CSR involves the conduct of a business so that it is economically profitable, law abiding, ethical, and socially supportive. To be socially responsible, profitability and obedience to the law are foremost conditions to discuss the firm's ethics and the extent to which it supports the society in which it exists with contributions of money, time, and talent. Thus, CSR is composed of four dimensions: economic, legal, ethical, and philanthropic [24, 25] and the selection of the evaluation factor for each dimension would be a complicated issue. According to these four dimensions, some appropriate evaluation indexes are identified via Delphi method in Step 1, and the correlation among the evaluation indexes is calculated via DEMATEL method in Step 2. Then, in Step 3, HDMSM adopts ANP to evaluate the important 


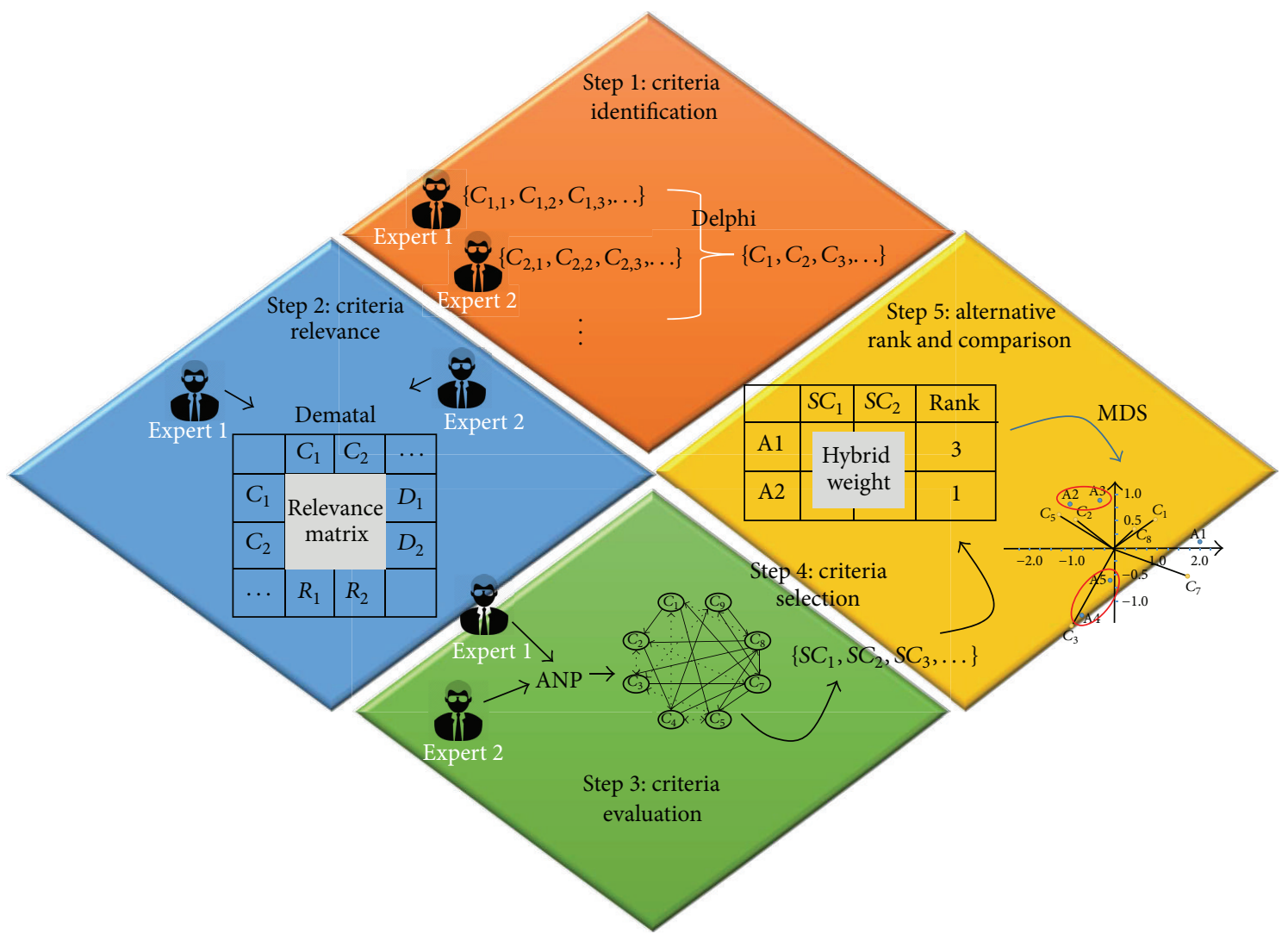

FIGURE 1: Hybrid decision-making support model (HDMSM).

ranking of these evaluation indexes for an enterprise to implement its corporate social responsibility and for different interested parties in connection with the enterprise. Finally, in Step 4, HDMSM selects 10 critical indexes through composite important weight and compares the similarity and dissimilarity among the interested parties via MDS in Step 5.

4.1. Criteria Identification. To make complicate multicriteria decision, like evaluation factors of CSR, it is necessary to select dimensions, criteria, and available alternatives as evaluation factors. Table 1 summarized some previous researches related to CSR. In total, there are 4 groups of evaluation dimensions and 28 evaluation indexes (i.e., evaluation criteria). Furthermore, five clusters of interested parties are chosen, namely, suppliers (A1), shareholders (A2), employees (A3), customers (A4), and the general public (A5), as the alternatives in this study.

To implement the case study, five domain experts were invited to form a decision-making team and fulfill a Delphi expert questionnaire that consists of 28 CSR evaluation criteria. The expert gave each criterion a score between 0 and 100 points. Then, for two discussion rounds, the experts gradually reached a consensus on the target decision problem (i.e., CDI < 0.05). According to the average score of decision criteria (the threshold is set 60 -points), some criteria are deleted from the candidate pool of decision criteria.
For the remained criteria, to uniform evaluation scale, the normalization process was conducted to obtain the rating weight for each CSR evaluation criteria as shown in Table 2. For illustration, some evaluation criteria (such as P1, P2, and L5) are more influential for business to solve CSR decision problem.

4.2. Establishment of Criteria Correlation. After the CSR evaluation criteria were identified via Delphi method in Step 1, DEMATEL expert questionnaire interview was implemented to determine the relation and the degree of mutual influence among the criteria to generate a direct relation matrix. The questionnaire scaling is 0 to 3 points in which 0 indicates no relation and 3 indicates a significant relation among the decision criteria [21]. A DEMATEL questionnaire sample is shown in Table 3.

4.3. Calculate Prominence of Criteria. After obtaining the direct relation matrix, formula (4) can be used to calculate and generate a direct/indirect relation matrix as shown in Table 4.

According to the direct/indirect relation matrix in Table 4, the sum of the column and the row is denoted by $D_{i}$ and $R_{j}$, respectively. $D_{i}$ represents the sum of the criterion $i$ influencing other criteria, $R_{j}$ represents the sum of the criterion $j$ being affected by other criteria, and the 
TABLE 1: CSR dimensions and criteria selection.

\begin{tabular}{|c|c|c|}
\hline Dimensions & & Evaluation criteria \\
\hline \multirow{7}{*}{$\begin{array}{l}\text { Economic } \\
\text { responsibilities }\end{array}$} & E1 & Reasonable product prices \\
\hline & E2 & Transparent business operations \\
\hline & E3 & $\begin{array}{l}\text { Avoid price collusion with any } \\
\text { competitor }\end{array}$ \\
\hline & $\mathrm{E} 4$ & Stimulate local economic development \\
\hline & E5 & Increase employment opportunities \\
\hline & E6 & $\begin{array}{l}\text { Maximum possible profits for the } \\
\text { organization }\end{array}$ \\
\hline & E7 & Honour agreed-upon contracts \\
\hline \multirow{7}{*}{$\begin{array}{l}\text { Legal } \\
\text { responsibilities }\end{array}$} & $\mathrm{L} 1$ & $\begin{array}{l}\text { Implement the consumer protection } \\
\text { act }\end{array}$ \\
\hline & $\mathrm{L} 2$ & $\begin{array}{l}\text { Ensure good and safe working } \\
\text { environment for employees }\end{array}$ \\
\hline & $\mathrm{L} 3$ & $\begin{array}{l}\text { Provide employees with the newest } \\
\text { information on pertinent laws }\end{array}$ \\
\hline & $\mathrm{L} 4$ & $\begin{array}{l}\text { Provide occupational injury } \\
\text { compensation and health insurance } \\
\text { systems }\end{array}$ \\
\hline & L5 & $\begin{array}{l}\text { Keep customer information } \\
\text { confidential and protect it against } \\
\text { illegal use }\end{array}$ \\
\hline & L6 & $\begin{array}{l}\text { Provide proper waste disposal and } \\
\text { reduce pollutant emissions }\end{array}$ \\
\hline & L7 & Actively inspect and certify products \\
\hline \multirow{10}{*}{$\begin{array}{l}\text { Ethical } \\
\text { responsibilities }\end{array}$} & M1 & $\begin{array}{l}\text { Provide consumers with customer } \\
\text { complaint service and thorough } \\
\text { follow-up service }\end{array}$ \\
\hline & M2 & $\begin{array}{l}\text { Provide employees with ways of } \\
\text { improving their working conditions }\end{array}$ \\
\hline & M3 & $\begin{array}{l}\text { Eschew exaggerated or false } \\
\text { advertisements }\end{array}$ \\
\hline & M4 & Pay salaries and wages on time \\
\hline & M5 & $\begin{array}{l}\text { Provide employees with a good } \\
\text { working environment }\end{array}$ \\
\hline & M6 & $\begin{array}{l}\text { Provide employees with fair selection, } \\
\text { promotion, termination, and } \\
\text { retirement systems }\end{array}$ \\
\hline & M7 & $\begin{array}{l}\text { Provide employees with reasonable } \\
\text { welfare and protection }\end{array}$ \\
\hline & M8 & $\begin{array}{l}\text { Provide employees with educational } \\
\text { training and living-related assistance }\end{array}$ \\
\hline & M9 & $\begin{array}{l}\text { Cooperate with the government in } \\
\text { energy-saving and carbon-reduction } \\
\text { policy }\end{array}$ \\
\hline & M10 & $\begin{array}{l}\text { Ensure transparent production } \\
\text { processes }\end{array}$ \\
\hline \multirow{4}{*}{$\begin{array}{l}\text { Philanthropic } \\
\text { responsibilities }\end{array}$} & $\mathrm{P} 1$ & Protect vulnerable social groups \\
\hline & $\mathrm{P} 2$ & Engage in charitable activities \\
\hline & P3 & Provide for community welfare \\
\hline & $\mathrm{P} 4$ & Use company resources efficiently \\
\hline
\end{tabular}

prominence score $\left(D_{i}+R_{i}\right)$ of each criterion can be obtained. The prominence scores are shown in Table 5 . As an evaluation criterion has a higher prominence score $\left(D_{i}+R_{i}\right)$, it indicates that the evaluation criterion has a higher prominence for decision-making problem. For example, in Table 5, the decision criteria M7 (providing employees with reasonable welfare and protection) with the highest prominence score is identified as the strongest influence decision criteria in the CSR case study.

4.4. Construct the Network Structure of Evaluation Framework. In the previous step, DEMATEL generated the direct relation among the CSR evaluation criteria, as shown in Table 3 , and the direct relation was then used to plot a network structure of evaluation framework, as shown in Figure 2.

Next, an ANP expert questionnaire was designed based on the network structure of evaluation framework. Total 15 interviewers finished the ANP questionnaires. The 15 interviewers included 3 middle-high level managers from different companies. Taking economic responsibility dimension as an example, the pairwise comparisons for the criteria E1-E5 were conducted, and the 9-point paired-comparison scaling was used for rating [26] as shown in Table 6. The answers to the questionnaires must conform to the logic of transitivity. That is, for illustration, in a questionnaire, when E1 $>$ E2 and E2 $>\mathrm{E} 3$, then the condition of E1 > E3 must exist. If not, the questionnaire is considered an invalid questionnaire.

4.5. Criteria Weighting and Priority Ranking. The collected questionnaires were further analyzed and processed using ANP to create an unweighted super matrix as shown in Table 7. The values in the matrix are the relative weights of the CSR evaluation criteria under each question in the ANP expert questionnaire. For instance, based on E3, the relative weights of L1 and M1 obtained from the pairwise comparison are 0.75 and 0.25 , respectively.

We cross-multiplied the values in each row of the unweighted super matrix by the weight of the dimension, respectively, and then a weighted super matrix can be obtained as shown in Table 8. The weight of each dimension is determined according to the expert's feedback. In this case, the weights of the four dimensions of economic responsibility, legal responsibility, moral responsibility, and philanthropic responsibility are $0.25,0.4,0.2$, and 0.15 , respectively.

To get a uniform weighted scale of super matrix, the normalization is implemented. A limit super matrix is shown in Table 9. The normalized matrix (in Table 8) is multiplied by itself repeatedly to convert the values (by row) into a limit value and generate the limit super matrix, wherein the values of each row are the importance weights of the CSR evaluation criteria.

According to the above MCDM method, the importance weights or scores for three groups of the CSR evaluation criteria are derived. However, the use of the results from one single decision-making analytic method to determine the importance level of each of the evaluation criteria to the overall decision problem seems to be too arbitrary and less persuasive and might even cause bias in determining the target decision, which obviously deviates from the initial purpose of employing different decision-making analytic 
TABLE 2: CDI and rating weights of CSR criteria.

\begin{tabular}{|c|c|c|c|c|c|c|c|c|c|c|}
\hline \multirow{2}{*}{ (D) } & \multirow{2}{*}{ (C) } & \multicolumn{5}{|c|}{ Score of final round } & \multirow{2}{*}{$\sigma$} & \multirow{2}{*}{ CDI } & \multirow{2}{*}{ Means } & \multirow{2}{*}{$\begin{array}{l}\text { Rating weight by } \\
\text { normalization }\end{array}$} \\
\hline & & 1 & 2 & 3 & 4 & 5 & & & & \\
\hline \multirow{7}{*}{ Economic } & E1 & 90 & 90 & 80 & 85 & 90 & 4.47 & 0.050 & 87.0 & 0.053 \\
\hline & $\mathrm{E} 2$ & 90 & 95 & 85 & 85 & 90 & 4.18 & 0.047 & 89.0 & 0.054 \\
\hline & E3 & 75 & 70 & 75 & 70 & 80 & 4.18 & 0.047 & 74.0 & 0.045 \\
\hline & $\mathrm{E} 4$ & 75 & 70 & 70 & 75 & 75 & 2.74 & 0.031 & 73.0 & 0.045 \\
\hline & E5 & 85 & 80 & 80 & 80 & 75 & 3.54 & 0.040 & 80.0 & 0.049 \\
\hline & E6 & 55 & 60 & 60 & 55 & 50 & 4.18 & 0.047 & 56.0 & (deleted) \\
\hline & E7 & 55 & 60 & 60 & 55 & 55 & 2.74 & 0.031 & 57.0 & (deleted) \\
\hline \multicolumn{9}{|c|}{ Sum of nondeleted mean: } & 403.0 & - \\
\hline \multirow{7}{*}{ Legal } & L1 & 85 & 80 & 85 & 90 & 85 & 3.54 & 0.038 & 85.0 & 0.052 \\
\hline & $\mathrm{L} 2$ & 75 & 85 & 80 & 80 & 77 & 3.78 & 0.041 & 79.4 & 0.048 \\
\hline & L3 & 75 & 78 & 70 & 80 & 80 & 4.22 & 0.046 & 76.6 & 0.047 \\
\hline & L4 & 70 & 75 & 72 & 78 & 75 & 3.08 & 0.034 & 74.0 & 0.045 \\
\hline & L5 & 90 & 95 & 90 & 90 & 95 & 2.74 & 0.030 & 92.0 & 0.056 \\
\hline & L6 & 85 & 87 & 90 & 93 & 95 & 4.12 & 0.045 & 90.0 & 0.055 \\
\hline & L7 & 75 & 70 & 80 & 76 & 73 & 3.70 & 0.040 & 74.8 & 0.046 \\
\hline \multicolumn{9}{|c|}{ Sum of nondeleted mean: } & 571.8 & - \\
\hline \multirow{10}{*}{ Ethical } & M1 & 85 & 80 & 83 & 88 & 90 & 3.96 & 0.044 & 85.2 & 0.052 \\
\hline & M2 & 61 & 62 & 55 & 54 & 55 & 3.78 & 0.042 & 57.4 & (deleted) \\
\hline & M3 & 55 & 54 & 50 & 45 & 53 & 4.04 & 0.045 & 55.0 & (deleted) \\
\hline & M4 & 70 & 65 & 68 & 73 & 70 & 2.95 & 0.033 & 69.2 & 0.042 \\
\hline & M5 & 45 & 53 & 52 & 50 & 47 & 3.36 & 0.037 & 49.4 & (deleted) \\
\hline & M6 & 70 & 77 & 75 & 73 & 80 & 3.81 & 0.042 & 75.0 & 0.046 \\
\hline & M7 & 65 & 63 & 60 & 70 & 66 & 3.70 & 0.041 & 64.8 & 0.040 \\
\hline & M8 & 45 & 48 & 45 & 52 & 50 & 3.08 & 0.034 & 48.0 & (deleted) \\
\hline & M9 & 90 & 93 & 85 & 88 & 95 & 3.96 & 0.044 & 90.2 & 0.055 \\
\hline & M10 & 85 & 88 & 90 & 93 & 90 & 2.95 & 0.033 & 89.2 & 0.054 \\
\hline \multicolumn{9}{|c|}{ Sum of nondeleted mean: } & 473.6 & - \\
\hline \multirow{4}{*}{ Philanthropic } & $\mathrm{P} 1$ & 98 & 90 & 95 & 95 & 100 & 3.78 & 0.040 & 95.6 & 0.058 \\
\hline & $\mathrm{P} 2$ & 95 & 90 & 92 & 96 & 95 & 2.51 & 0.026 & 93.6 & 0.057 \\
\hline & P3 & 55 & 60 & 56 & 58 & 55 & 2.17 & 0.023 & 56.8 & (deleted) \\
\hline & $\mathrm{P} 4$ & 61 & 63 & 55 & 54 & 55 & 4.10 & 0.043 & 57.6 & (deleted) \\
\hline \multicolumn{9}{|c|}{ Sum of nondeleted mean: } & 189.2 & 1.000 \\
\hline
\end{tabular}

$\mathrm{D}$ denotes dimension, $\mathrm{C}$ denotes criterion, $\sigma$ denotes standard deviation, and CDI denotes consensus deviation index.

methods. To avoid the above condition and to upgrade the accuracy of results from decision-making analysis, this study further multiplied the importance weights of the criteria derived with Delphi and ANP by the prominence scores of the criteria found by DEMATEL. However, since some criteria have a prominence score less than 1 (i.e., $D_{i}+R_{i}<1$ ) that would result in an even smaller value after multiplication, it is necessary to add 1 to each of the prominence scores before multiplying the importance weights by the prominence scores. Finally, a composite importance weight was obtained for each of the CSR evaluation criteria, and a priority ranking of all criteria was obtained according to their composite importance weights. The calculation results are shown in Table 10.

As shown in Table 10, the ranking of the criteria based on the composite importance weights is not exactly the same priority ranking for all three MCDM methods, and some criteria have quite different importance levels in different ways of ranking. For instance, referring to the prominence score of DEMATEL, E2 is the third important index. However, 
TABLE 3: Direct relation matrix.

\begin{tabular}{lcccccccccccccccccccc}
\hline Criteria & E1 & E2 & E3 & E4 & E5 & L1 & L2 & L3 & L4 & L5 & L6 & L7 & M1 & M4 & M6 & M7 & M9 & M10 & P1 & P2 \\
\hline E1 & 0 & 0 & 3 & 2 & 0 & 0 & 0 & 0 & 0 & 0 & 0 & 0 & 0 & 0 & 0 & 0 & 0 & 0 & 0 & 0 \\
E2 & 1 & 0 & 3 & 0 & 0 & 0 & 0 & 0 & 0 & 1 & 2 & 3 & 0 & 0 & 2 & 0 & 0 & 3 & 0 & 0 \\
E3 & 0 & 1 & 0 & 0 & 0 & 1 & 0 & 0 & 0 & 0 & 0 & 0 & 1 & 0 & 0 & 0 & 0 & 0 & 0 & 0 \\
E4 & 0 & 0 & 0 & 0 & 3 & 0 & 0 & 0 & 0 & 0 & 0 & 0 & 0 & 0 & 0 & 0 & 0 & 0 & 0 & 0 \\
E5 & 0 & 0 & 0 & 1 & 0 & 0 & 0 & 0 & 0 & 0 & 0 & 0 & 0 & 0 & 0 & 0 & 0 & 0 & 0 & 0 \\
\hline L1 & 3 & 0 & 2 & 0 & 0 & 0 & 0 & 0 & 0 & 3 & 0 & 3 & 2 & 0 & 0 & 0 & 0 & 1 & 0 & 0 \\
L2 & 0 & 0 & 0 & 0 & 0 & 0 & 0 & 0 & 2 & 0 & 1 & 0 & 0 & 0 & 0 & 0 & 0 & 0 & 0 & 0 \\
L3 & 0 & 0 & 0 & 0 & 0 & 0 & 0 & 0 & 0 & 0 & 0 & 0 & 0 & 3 & 0 & 1 & 0 & 0 & 0 & 0 \\
L4 & 0 & 0 & 0 & 0 & 0 & 0 & 3 & 0 & 0 & 0 & 0 & 0 & 0 & 0 & 0 & 3 & 0 & 0 & 1 & 0 \\
L5 & 0 & 0 & 0 & 0 & 0 & 3 & 0 & 0 & 0 & 0 & 0 & 0 & 0 & 0 & 0 & 0 & 0 & 0 & 0 & 0 \\
L6 & 0 & 0 & 0 & 0 & 0 & 0 & 0 & 0 & 0 & 0 & 0 & 0 & 0 & 0 & 0 & 0 & 0 & 0 & 0 & 0 \\
L7 & 0 & 0 & 0 & 0 & 0 & 0 & 0 & 0 & 0 & 0 & 0 & 0 & 0 & 0 & 0 & 0 & 0 & 0 & 0 & 0 \\
\hline M1 & 0 & 0 & 0 & 0 & 0 & 0 & 0 & 0 & 0 & 0 & 0 & 0 & 0 & 0 & 0 & 0 & 0 & 0 & 0 & 0 \\
M4 & 0 & 0 & 0 & 0 & 1 & 0 & 0 & 3 & 0 & 0 & 0 & 0 & 0 & 0 & 0 & 0 & 0 & 0 & 0 & 0 \\
M6 & 0 & 0 & 0 & 0 & 1 & 0 & 2 & 0 & 0 & 0 & 0 & 0 & 0 & 0 & 0 & 0 & 0 & 0 & 0 & 0 \\
M7 & 0 & 0 & 0 & 0 & 0 & 0 & 3 & 3 & 3 & 0 & 0 & 0 & 0 & 1 & 2 & 0 & 0 & 0 & 0 & 0 \\
M9 & 0 & 0 & 0 & 0 & 0 & 0 & 0 & 0 & 0 & 0 & 0 & 0 & 0 & 0 & 0 & 0 & 0 & 0 & 0 & 0 \\
M10 & 0 & 0 & 0 & 0 & 0 & 0 & 0 & 0 & 0 & 0 & 3 & 3 & 0 & 0 & 0 & 0 & 3 & 0 & 0 & 0 \\
\hline P1 & 0 & 0 & 0 & 1 & 3 & 0 & 0 & 0 & 0 & 0 & 0 & 0 & 0 & 0 & 0 & 0 & 0 & 0 & 0 & 2 \\
P2 & 0 & 0 & 0 & 0 & 0 & 0 & 0 & 0 & 0 & 0 & 0 & 0 & 0 & 0 & 0 & 0 & 0 & 0 & 3 & 0 \\
\hline
\end{tabular}

TABLE 4: Direct/indirect relation matrix.

\begin{tabular}{|c|c|c|c|c|c|c|c|c|c|c|c|c|c|c|c|c|c|c|c|c|}
\hline Crit & $\mathrm{E} 1$ & E2 & E3 & $\mathrm{E} 4$ & E5 & 1 & 2 & 3 & 4 & .5 & 6 & L7 & M1 & 14 & 16 & M7 & M9 & M10 & P1 & 2 \\
\hline $\mathrm{E} 1$ & 0.00 & 0.01 & 0.21 & 0.14 & 0.03 & 0.01 & 0.00 & 0.00 & 0.00 & 0.00 & 0.00 & 0.01 & 0.02 & 0.00 & 0.00 & 0.00 & 0.00 & 0.00 & 0.00 & 0.00 \\
\hline F? & 0.07 & 01 & 22 & 01 & 01 & 03 & 02 & 00 & 00 & .07 & .18 & 25 & רח & .00 & .14 & .00 & .04 & .20 & .00 & .00 \\
\hline 3 & ?ר & & & 0 & 0 & 7 & 0 & 0 & 0 & ר & 1 & 3 & & & 01 & 00 & 00 & 02 & 00 & .00 \\
\hline $\mathrm{E} 4$ & 0.00 & 00 & 00 & 0.01 & 0.20 & 0.00 & 0.00 & 0.00 & 0.00 & 0.00 & 0.00 & 0.00 & 0.00 & 0.00 & 0.00 & 0.00 & 0.00 & 00 & 0.00 & 0.00 \\
\hline E5 & 0.00 & 0.00 & 0.00 & 0.07 & 0.01 & 0.00 & 0.00 & 0.00 & 0.00 & 0.00 & 0.00 & 0.00 & 0.00 & 0.00 & 0.00 & 0.00 & 0.00 & 0.00 & 0.00 & 0.00 \\
\hline L1 & 0.21 & 0.01 & 0.19 & 0.03 & 0.01 & 0.05 & 0.00 & 0.00 & 0.00 & 0.21 & 0.02 & 0.23 & 0.15 & 0.00 & 0.00 & 0.00 & 0.01 & 0.07 & 0.00 & 0.00 \\
\hline L2 & 0.00 & 0.00 & .00 & 0.00 & 0.00 & 0.00 & 0.04 & 0.01 & 0.14 & 0.00 & 0.07 & 0.00 & 0.00 & 0.00 & 0.00 & 0.03 & 0.00 & 0.00 & .01 & 0.00 \\
\hline 3 & 0.00 & 0.00 & 00 & 0.00 & 0.02 & 00 & 0.02 & 0.06 & 0.02 & 0.00 & 0.00 & 0.00 & 00 & 22 & 01 & 07 & 00 & 00 & 00 & .00 \\
\hline 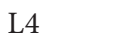 & 0.00 & 0.00 & 00 & 0.01 & 0.02 & .00 & .26 & .05 & 0.08 & 0.00 & 0.02 & 0.00 & 0.00 & 0.02 & 0.03 & 0.22 & 0.00 & 0.00 & 0.07 & 0.01 \\
\hline L5 & 0.04 & 0.00 & 0.04 & 0.01 & 0.00 & 0.21 & 0.00 & 0.00 & 0.00 & 0.04 & 0.00 & 0.05 & 0.03 & 0.00 & 0.00 & 0.00 & 0.00 & .01 & 0.00 & 0.00 \\
\hline L6 & 0.00 & $0 \Omega 0$ & .00 & 00 & 00 & חم & 0.00 & مO & $0 \Omega 0$ & $0 \Omega 0$ & $0 \Omega 0$ & 0.00 & 0.00 & 0.00 & 0.00 & 0.00 & 00 & .00 & .00 & 0.00 \\
\hline 7 & & $0 \Omega$ & 0 & & & & & & & & 0 & & & & & & & & & 0.00 \\
\hline & & & & & & & & .00 & & 0.00 & 0.00 & & & & 0.00 & 0.00 & 0.00 & 0.00 & 0.00 & 0.00 \\
\hline M4 & 0.00 & 0.00 & 0.00 & 0.00 & 0.07 & 0.00 & 0.00 & 0.21 & 0.00 & 0.00 & 0.00 & 0.00 & 0.00 & 0.04 & 0.00 & 0.01 & 0.00 & 0.00 & 0.00 & 0.00 \\
\hline M6 & 0.00 & 0.00 & 0.00 & 0.00 & 0.07 & 0.00 & 0.14 & 0.00 & 0.02 & 0.00 & 0.01 & 0.00 & 0.00 & 0.00 & 0.00 & 0.00 & 0.00 & 0.00 & 0.00 & 0.00 \\
\hline M7 & 0.00 & 0.00 & 0.00 & 0.00 & 0.02 & 0.00 & 0.28 & 0.24 & 0.25 & 0.00 & 0.02 & 0.00 & 0.00 & 0.12 & 0.14 & 0.07 & 0.00 & 0.00 & 0.02 & 0.00 \\
\hline M9 & 0.00 & 0.00 & 0.00 & 0.00 & 0.00 & 0.00 & 0.00 & 0.00 & 0.00 & 0.00 & 0.00 & 0.00 & 0.00 & 0.00 & 0.00 & 0.00 & 0.00 & 0.00 & 0.00 & 0.00 \\
\hline M10 & 0.00 & 0.00 & 0.00 & 0.00 & 0.00 & 0.00 & 0.00 & 0.00 & 0.00 & 0.00 & 0.20 & 0.20 & 0.00 & 0.00 & 0.00 & 0.00 & 0.20 & 0.00 & 0.00 & 0.00 \\
\hline $\mathrm{P} 1$ & 0.00 & 0.00 & 0.00 & 0.08 & 0.22 & 0.00 & 0.00 & 0.00 & 0.00 & 0.00 & 0.00 & 0.00 & 0.00 & 0.00 & 0.00 & 0.00 & 0.00 & 0.00 & 0.03 & 0.14 \\
\hline P2 & 0.00 & 0.00 & 0.00 & 0.02 & 0.04 & 0.00 & 0.00 & 0.00 & 0.00 & 0.00 & 0.00 & 0.00 & 0.00 & 0.00 & 0.00 & 0.00 & 0.00 & 0.00 & 0.21 & 0.03 \\
\hline
\end{tabular}

if taken the composite weight into consideration, the same index of E2 is the eleventh. For another example, according to the Delphi weight, P1 and P2 are the top two important CSR evaluation criteria but only rank last two in the priority ranking based on the composite weight. As demonstration, both the analysis results of all MCDM methodologies and composite weights have the reference values.
4.6. Alternative Comparison. In general, there are more than one alternative for decision maker to choose for problem solving. For each alternative, they may have levels of effect on different evaluation criteria. Therefore, according to described analytic results, in the study, the importance weight threshold is set to 0.05 for top 10 CSR critical criteria selection. And then, a second pairwise comparison is 
TABLE 5: Prominence of CSR evaluation criteria.

\begin{tabular}{|c|c|c|c|c|}
\hline & CSR evaluation criteria & $R_{i}$ & $D_{i}$ & $D_{i}+R_{i}$ \\
\hline E1 & Reasonable product prices & 0.35 & 0.43 & 0.78 \\
\hline E2 & $\begin{array}{l}\text { Transparent business } \\
\text { operations }\end{array}$ & 0.11 & 1.30 & 1.41 \\
\hline E3 & $\begin{array}{l}\text { Avoid price collusion with } \\
\text { any competitor }\end{array}$ & 0.58 & 0.36 & 0.94 \\
\hline E4 & $\begin{array}{l}\text { Stimulate local economic } \\
\text { development }\end{array}$ & 0.39 & 0.22 & 0.61 \\
\hline E5 & $\begin{array}{l}\text { Increase employment } \\
\text { opportunities }\end{array}$ & 0.82 & 0.08 & 0.90 \\
\hline $\mathrm{L} 1$ & $\begin{array}{l}\text { Implement the consumer } \\
\text { protection act }\end{array}$ & 0.38 & 1.03 & 1.41 \\
\hline L2 & $\begin{array}{l}\text { Ensure good and safe } \\
\text { working environment for } \\
\text { employees }\end{array}$ & 0.85 & 0.31 & 1.16 \\
\hline L3 & $\begin{array}{l}\text { Provide employees with the } \\
\text { newest information on } \\
\text { pertinent laws }\end{array}$ & 0.56 & 0.42 & 0.98 \\
\hline $\mathrm{L} 4$ & $\begin{array}{l}\text { Provide occupational injury } \\
\text { compensation and health } \\
\text { insurance systems }\end{array}$ & 0.53 & 0.80 & 1.32 \\
\hline L5 & $\begin{array}{l}\text { Keep customer information } \\
\text { confidential and protect it } \\
\text { against illegal use }\end{array}$ & 0.35 & 0.41 & 0.76 \\
\hline L6 & $\begin{array}{l}\text { Provide proper waste } \\
\text { disposal and reduce } \\
\text { pollutant emissions }\end{array}$ & 0.53 & 0.00 & 0.53 \\
\hline L7 & $\begin{array}{l}\text { Actively inspect and certify } \\
\text { products }\end{array}$ & 0.67 & 0.00 & 0.67 \\
\hline M1 & $\begin{array}{l}\text { Provide consumers with } \\
\text { customer complaint service } \\
\text { and thorough follow-up } \\
\text { service }\end{array}$ & 0.29 & 0.00 & 0.29 \\
\hline M4 & $\begin{array}{l}\text { Pay salaries and wages on } \\
\text { time }\end{array}$ & 0.41 & 0.36 & 0.76 \\
\hline M6 & $\begin{array}{l}\text { Provide employees with fair } \\
\text { selection, promotion, } \\
\text { termination, and } \\
\text { retirement systems }\end{array}$ & 0.34 & 0.41 & 0.74 \\
\hline M7 & $\begin{array}{l}\text { Provide employees with } \\
\text { reasonable welfare and } \\
\text { protection }\end{array}$ & 0.41 & 1.18 & 1.59 \\
\hline M9 & $\begin{array}{l}\text { Cooperate with the } \\
\text { government in } \\
\text { energy-saving and } \\
\text { carbon-reduction policy }\end{array}$ & 0.26 & 0.00 & 0.26 \\
\hline M10 & $\begin{array}{l}\text { Ensure transparent } \\
\text { production processes }\end{array}$ & 0.31 & 0.60 & 0.91 \\
\hline P1 & $\begin{array}{l}\text { Protect vulnerable social } \\
\text { groups }\end{array}$ & 0.34 & 0.47 & 0.81 \\
\hline P2 & $\begin{array}{l}\text { Engage in charitable } \\
\text { activities }\end{array}$ & 0.18 & 0.29 & 0.47 \\
\hline
\end{tabular}

conducted for the five interested clusters (i.e., the alternatives used in this study). To facilitate the subsequent alternative similarity analysis, the 9-point paired-comparison scaling was also used for measurement. Finally, the relative weights of the interested clusters under the selected 10 critical criteria were obtained as shown in Table 11.

Based on Table 11, the Euclidean distance between any two of the interested clusters is further calculated and the Euclidean distance matrix is created as shown in Table 12. In the Euclidean distance matrix, the smaller the value between two alternatives (such as the interested parties), the closer the distance between them, meaning a higher similarity between two alternatives. Then, according to this matrix, the positions of the interested clusters in a two-dimensional coordinate system can be located, and a perceptual map of alternative allocation can be plotted.

From the perceptual map shown in Figure 3, the similarity and dissimilarity among the clusters (such as three elliptic areas in Figure 3) can be clarified clearly. For CSR example in Section 4, the perceptual map can visualize the evaluation criteria for CSR from different perspectives (such as A1 to A5) and provide decision maker with detail information. As shown in Figure 3, for illustration, we can find that the consideration of shareholder is similar to supplier and employee while business is intended to plan and implement CSR issues. Referring to the analysis result of the proposed HDMSM, decision maker can develop a solution that fulfilled the most correct decision-making policy.

\section{Conclusions and Further Work}

MCDM has been an important issue and many researches are devoted to help people make better decision. Particularly, some decision-making analytic methodologies (such as ANP and DEMTEAL) and information technologies (such as DSS and GDSS) can help decision makers to analyze the decision problem, collect information, indicate the available alternatives, and so on. However, the MCDM involves multiple decision criteria and, the worst, these criteria might mutually influence one another to lead to a complicated situation. Decision making is a sophisticated art and decision makers indeed require some help.

This study proposed a hybrid decision-making support model (HDMSM) that is an integrated GDSS architecture consisting of five steps, namely, criteria identification, criteria correlation, criteria evaluation, criteria selection, and alternative rank and comparison. Further, HDMSM appropriately integrates four systemic decision approaches (Delphi, DEMATEL, ANP, and MDS) to help the decision maker with alternative rank and selection issue. HDMSM consists of five steps. In Step 1, HDMSM adopts Delphi to collect and identify the decision criteria from domain experts. After that, in Step 2, domain experts use DEMATEL to evaluate the correlation among the selected criteria (in Step 1) and then generate a relation matrix of these decision criteria. Then, in Step 3, HDMSM adopts ANP to calculate the complicate correlation and importance weight for each decision criterion in Step 4. Finally, in Step 5, MDS can rank all available alternatives according to the importance weights and visualize the similarity (or difference) among all available alternatives.

A case study was implemented based on the proposed HDMSM. The case study intends to find out the important indexes of corporate social responsibility (CSR) from 
TABLE 6: Sample answer in pairwise comparison (based on the dimension of economic).

\begin{tabular}{|c|c|c|c|c|c|c|c|c|c|c|}
\hline \multicolumn{3}{|c|}{ Absolutely important } & \multicolumn{6}{|c|}{ - Equally important $\longrightarrow$} & \multicolumn{2}{|c|}{ Absolutely important } \\
\hline Scaling & $9: 1$ & $7: 1$ & $5: 1$ & $3: 1$ & $1: 1$ & $1: 3$ & $1: 5$ & $1: 7$ & $1: 9$ & Scaling \\
\hline E1 & & & & $\mathrm{V}$ & & & & & & E2 \\
\hline E1 & & $\mathrm{V}$ & & & & & & & & E3 \\
\hline E1 & & & $\mathrm{V}$ & & & & & & & $\mathrm{E} 4$ \\
\hline E1 & & & & & & $\mathrm{V}$ & & & & E5 \\
\hline E2 & & & $\mathrm{V}$ & & & & & & & E3 \\
\hline E2 & & & & & $\mathrm{V}$ & & & & & $\mathrm{E} 4$ \\
\hline E2 & & & & & & & & & $\mathrm{V}$ & E5 \\
\hline E3 & & & & & $\mathrm{V}$ & & & & & $\mathrm{E} 4$ \\
\hline E3 & & & & & & & & & $\mathrm{V}$ & E5 \\
\hline $\mathrm{E} 4$ & & & & & & & & $\mathrm{~V}$ & & E5 \\
\hline
\end{tabular}

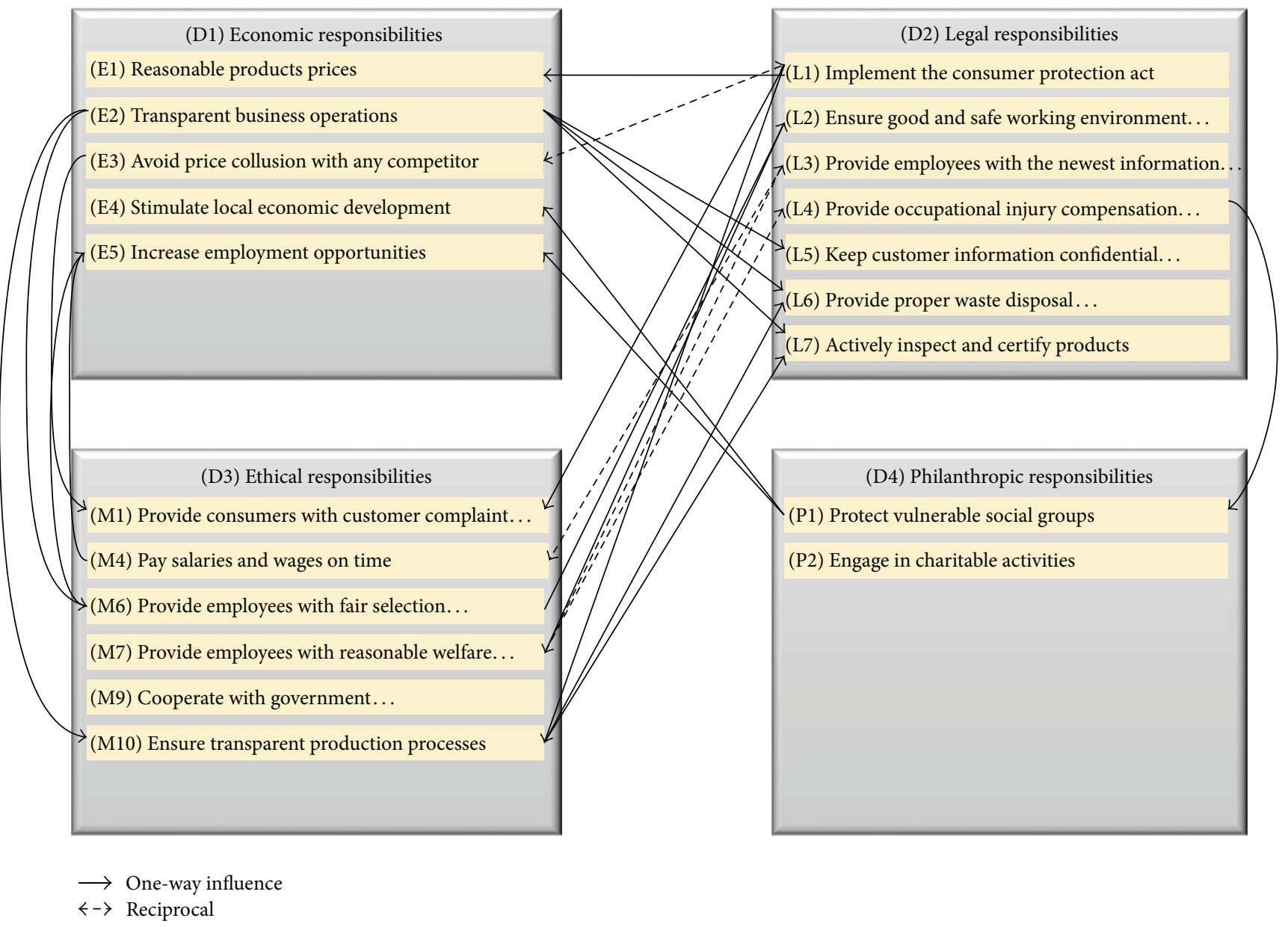

FIgURE 2: Network structure of the evaluation framework.

multiple perspectives. The case study results showed some interest findings. We found that "implementing the consumer protection act," "providing proper waste disposal and reduce pollutant emission," "keeping customer information confidential and protecting it against illegal use," "providing employees with the newest information of related laws," and "ensuring good and safe working environment for employees" are top five critical criteria for enterprises to implement their corporate social responsibility (CSR). Further, according to the similarity analysis for interested clusters, three groups of interest clusters can be formed, including the employees and shareholder as the first one group, the shareholders and suppliers as the second one, and the suppliers and customers as the last one group. The members of the same group 


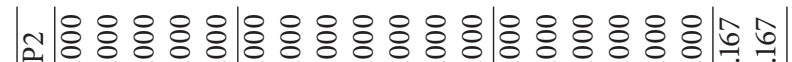

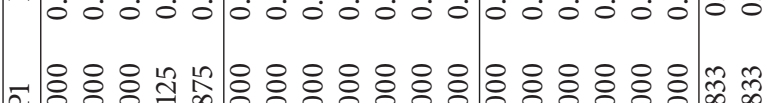

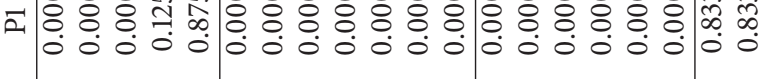

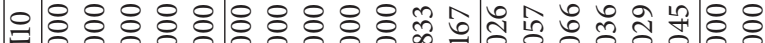
40000000000000000000000

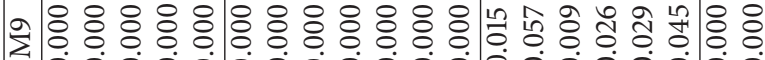

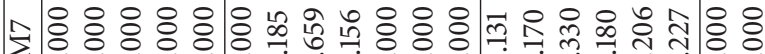

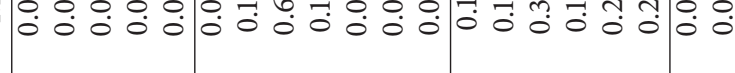

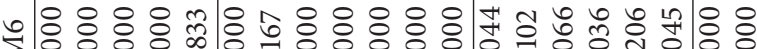

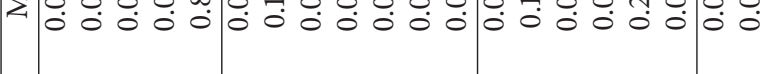
स

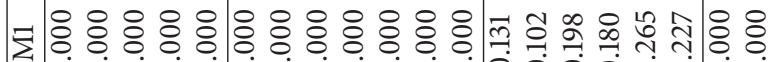

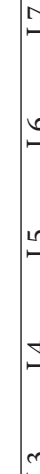

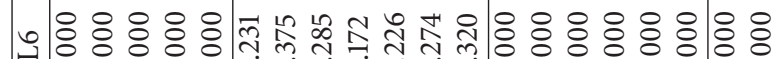
0.000000000000000000

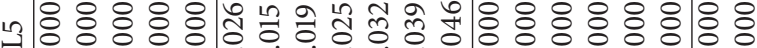

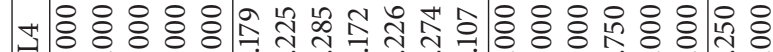

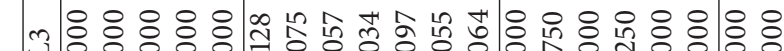
000000000000000000000

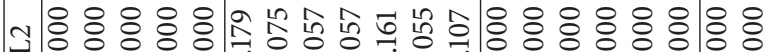

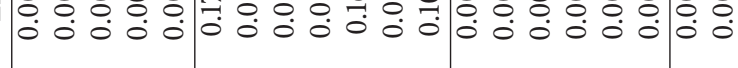

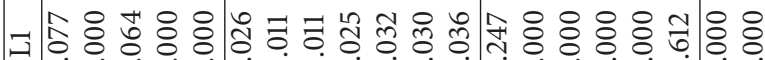

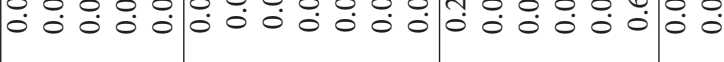

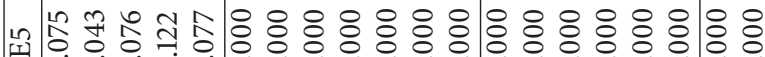
0.000 .000 .000 .000 .000 .00000

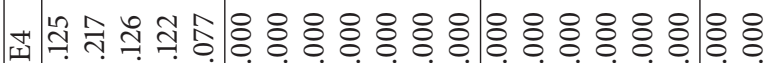

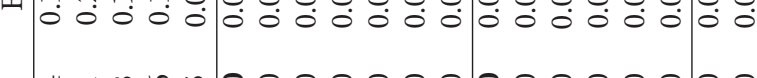

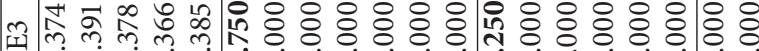

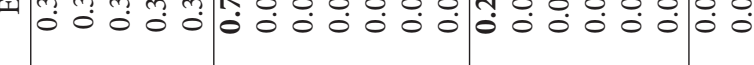

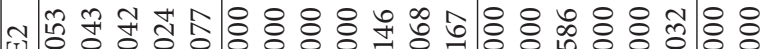

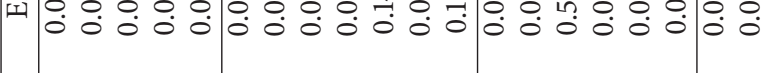

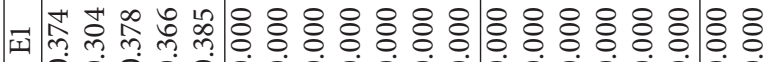
苞

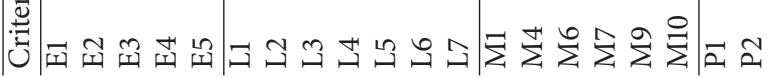




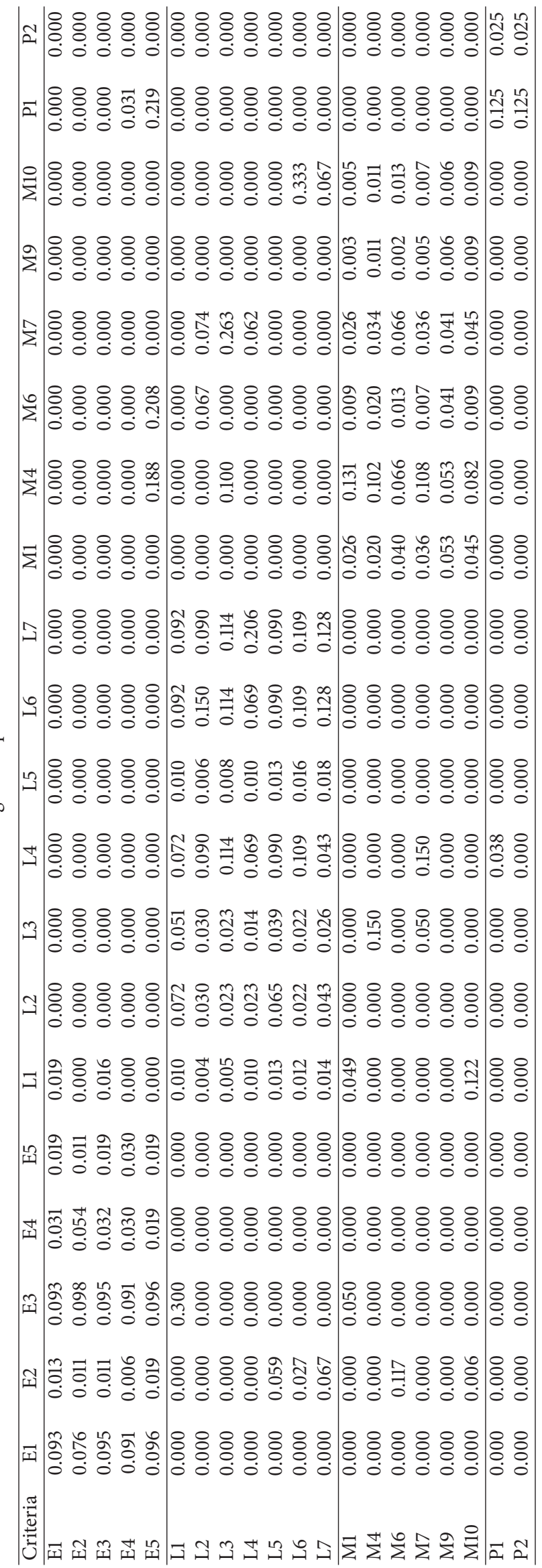




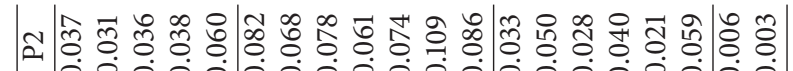
0000000000000000000000

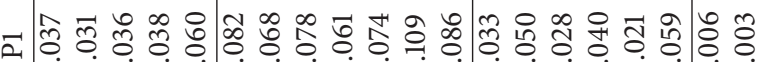
00000000000000000000000

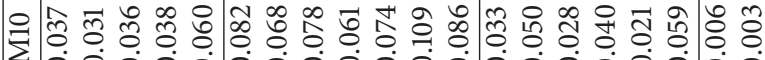

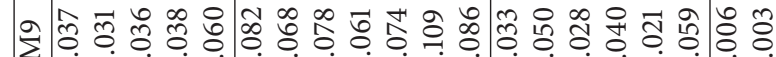
$\therefore 0.00000000000000000$

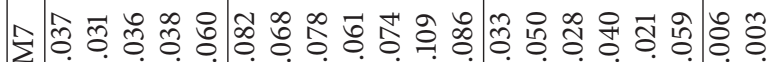

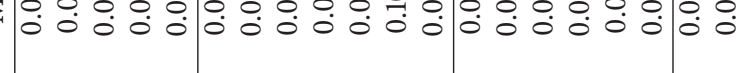

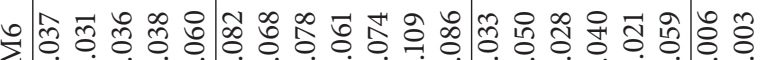
0000000000000000000000

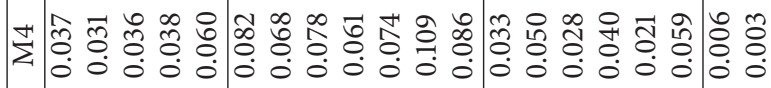
इ 00000000000000000000

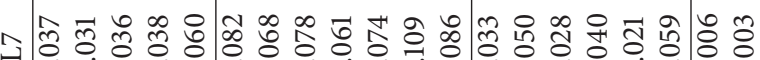
.

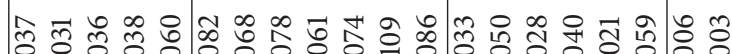
00000000000000000000

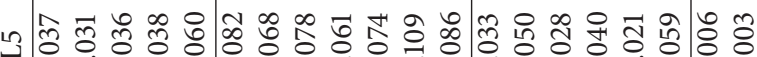
00000000000000000000

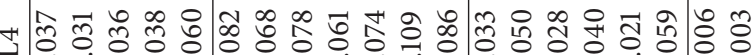
0000000000000000000.

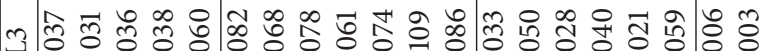
$\therefore 0: 000: 00: 00: 0000: 00$

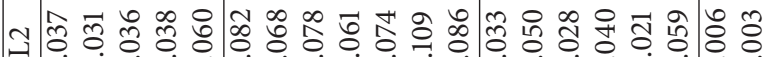

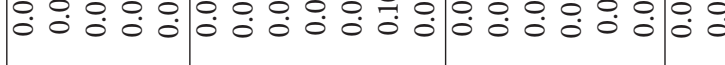

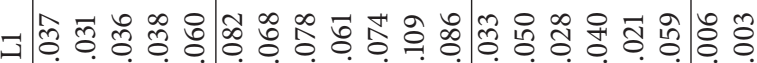
00000000000000000

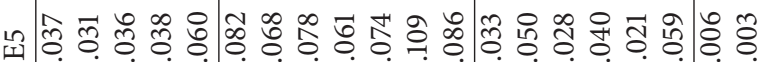

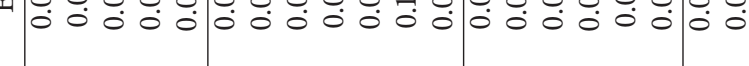

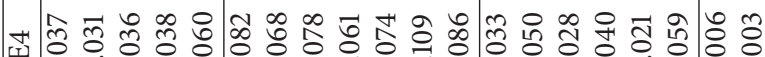
$=0.000 .000000000000000000$

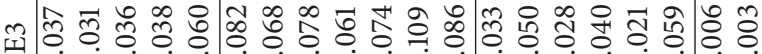
000000000000000000000

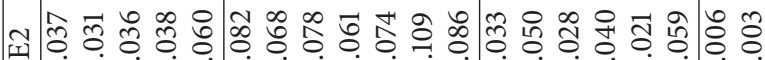
00000000000000000000

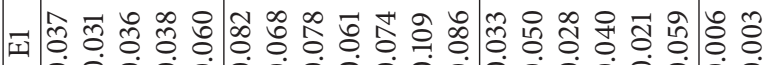
竎

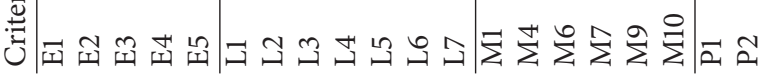


TABLE 10: Composite important weight and priority ranking of criteria.

\begin{tabular}{|c|c|c|c|c|c|c|}
\hline Criterion & $\begin{array}{c}\text { DEMETAL } \\
\text { prominence score }\end{array}$ & Delphi weight & ANP weight & Composite weight & $\begin{array}{l}\text { Normalization of } \\
\text { composite weight }\end{array}$ & General ranking \\
\hline E1 & 0.782 & 0.053 & 0.037 & 0.0035 & 0.038 & 13 \\
\hline $\mathrm{E} 2$ & 1.407 & 0.054 & 0.031 & 0.0040 & 0.043 & 11 \\
\hline E3 & 0.938 & 0.045 & 0.036 & 0.0032 & 0.034 & 14 \\
\hline $\mathrm{E} 4$ & 0.606 & 0.045 & 0.038 & 0.0027 & 0.029 & 15 \\
\hline E5 & 0.898 & 0.049 & 0.060 & 0.0055 & 0.059 & 9 \\
\hline $\mathrm{L} 1$ & 1.407 & 0.052 & 0.082 & 0.0102 & 0.109 & 1 \\
\hline L2 & 1.161 & 0.048 & 0.068 & 0.0071 & 0.076 & 5 \\
\hline L3 & 0.980 & 0.047 & 0.078 & 0.0072 & 0.077 & 4 \\
\hline L4 & 1.325 & 0.045 & 0.061 & 0.0064 & 0.068 & 7 \\
\hline L5 & 0.755 & 0.056 & 0.074 & 0.0073 & 0.078 & 3 \\
\hline L6 & 0.534 & 0.055 & 0.109 & 0.0092 & 0.098 & 2 \\
\hline L7 & 0.667 & 0.046 & 0.086 & 0.0066 & 0.070 & 6 \\
\hline M1 & 0.289 & 0.052 & 0.033 & 0.0022 & 0.024 & 17 \\
\hline M4 & 0.762 & 0.042 & 0.050 & 0.0037 & 0.040 & 12 \\
\hline M6 & 0.741 & 0.046 & 0.028 & 0.0023 & 0.024 & 16 \\
\hline M7 & 1.591 & 0.040 & 0.040 & 0.0041 & 0.044 & 10 \\
\hline M9 & 0.263 & 0.055 & 0.021 & 0.0015 & 0.016 & 18 \\
\hline M10 & 0.913 & 0.054 & 0.059 & 0.0061 & 0.065 & 8 \\
\hline $\mathrm{P} 1$ & 0.807 & 0.058 & 0.006 & 0.0006 & 0.007 & 19 \\
\hline P2 & 0.472 & 0.057 & 0.003 & 0.0002 & 0.003 & 20 \\
\hline Total & - & 1.000 & 1.000 & - & 1.000 & - \\
\hline
\end{tabular}

TABLE 11: Relative weights of alternatives under CSR criteria.

\begin{tabular}{lcccccccccccc}
\hline Interested parties & L1 & L6 & L5 & L3 & L2 & L7 & L4 & M10 & E5 & M7 & Sum of weight \\
\hline A1 suppliers & 0.049 & 0.042 & 0.047 & 0.252 & 0.049 & 0.047 & 0.529 & 0.270 & 0.051 & 0.061 & 1.396 \\
A2 shareholders & 0.052 & 0.165 & 0.125 & 0.122 & 0.212 & 0.252 & 0.151 & 0.096 & 0.222 & 0.514 & 1.912 \\
A3 employees & 0.147 & 0.217 & 0.214 & 0.036 & 0.537 & 0.529 & 0.047 & 0.046 & 0.563 & 0.210 & 2.547 \\
A4 customers & 0.571 & 0.052 & 0.042 & 0.520 & 0.041 & 0.066 & 0.220 & 0.522 & 0.048 & 0.171 & 2.254 \\
A5 general public & 0.181 & 0.523 & 0.572 & 0.070 & 0.162 & 0.106 & 0.053 & 0.065 & 0.116 & 0.043 & 1.891 \\
\hline Total & 1.000 & 1.000 & 1.000 & 1.000 & 1.000 & 1.000 & 1.000 & 1.000 & 1.000 & 1.000 & - \\
\hline
\end{tabular}

TABLE 12: Euclidean distance matrix for alternatives.

\begin{tabular}{|c|c|c|c|c|c|}
\hline Interested parties & $\begin{array}{c}\text { A1 } \\
\text { suppliers }\end{array}$ & $\begin{array}{c}\text { A2 } \\
\text { shareholders }\end{array}$ & $\begin{array}{c}\text { A3 } \\
\text { employees }\end{array}$ & $\begin{array}{c}\text { A4 } \\
\text { customers }\end{array}$ & $\begin{array}{c}\text { A5 } \\
\text { general public }\end{array}$ \\
\hline A1 suppliers & 0.000 & & & & \\
\hline A2 shareholders & 0.257 & 0.000 & & & \\
\hline A3 employees & 0.576 & 0.216 & 0.000 & & \\
\hline A4 customers & 0.258 & 0.423 & 0.726 & 0.000 & \\
\hline A5 general public & 0.423 & 0.307 & 0.385 & 0.565 & 0.000 \\
\hline
\end{tabular}

got closed viewpoint toward the CSR evaluation criteria. Therefore, to maximize the CSR policies effect, the reference to the analyzed results can help the enterprises to establish and develop their CSR strategies for particular interested cluster.
The proposed HDMSM can enable a group of decision makers to implement the MCDM effectively and help them to analyze the relation and degree of mutual influence among different evaluation factors. As the case study demonstrated, the HDMSM can locate the evaluation factors with relatively 


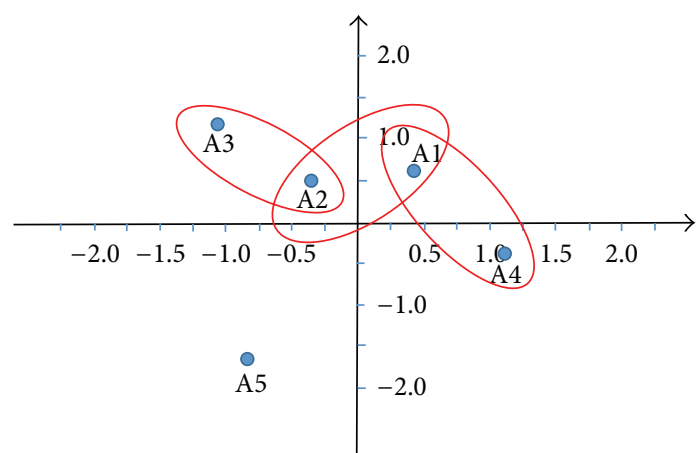

FIGURE 3: Perceptual map of alternative allocation.

significant and deep influence and conduct a cross analysis for different alternatives of the decision problem. Therefore, according to the analysis result, decision maker can choose the optimal alternative for decision problem solving. In the future, the HDMSM can be applied to various domains of decision problem, such as system introducing and enterprise resource planning. Also, the proposed HDMSM can be further combined with other decision-making analytic methods, such as association rules analysis, TOPSIS, or VIKOR, to upgrade the accuracy and effectiveness of the HDMSM in handling decision problems.

\section{Conflict of Interests}

The authors declare that there is no conflict of interests regarding the publication of this paper.

\section{References}

[1] K. Yoon and C.-L. Hwang, "Manufacturing plant location analysis by multiple attribute decision making: part I-singleplant strategy," International Journal of Production Research, vol. 23, no. 2, pp. 345-359, 1985.

[2] H. A. Simon, The New Science of Management Decision, Harper \& Row, New York, NY, USA, 1960.

[3] R. L. Keeney and H. Raiffa, Decision with Multiple Objectives: Preference and Value Tradeoffs, John Wiley \& Sons, New York, NY, USA, 1976.

[4] Y. H. Hung, S. C. T. Chou, and G. H. Tzeng, "Knowledge management adoption and assessment for SMEs by a novel MCDM approach," Decision Support Systems, vol. 51, no. 2, pp. 270-291, 2011.

[5] C.-H. Hsu, F.-K. Wang, and G.-H. Tzeng, "The best vendor selection for conducting the recycled material based on a hybrid MCDM model combining DANP with VIKOR," Resources, Conservation and Recycling, vol. 66, pp. 95-111, 2012.

[6] W.-Y. Chiu, G.-H. Tzeng, and H.-L. Li, "A new hybrid MCDM model combining DANP with VIKOR to improve e-store business," Knowledge-Based Systems, vol. 37, pp. 48-61, 2013.

[7] C. L. Hwang and K. Yoon, Multiple Attribute Decision Making: Methods and Application, Springer, New York, NY, USA, 1981.

[8] R. H. Sprague Jr., "A framework for the development of decision support systems," MIS Quarterly: Management Information Systems, vol. 4, no. 4, pp. 1-26, 1980.
[9] C. Koo, T. Hong, and J. Kim, "A decision support system for determining the optimal size of a new expressway service area: focused on the profitability," Decision Support Systems, vol. 67, pp. 9-20, 2014.

[10] J. Gottschlich and O. Hinz, "A decision support system for stock investment recommendations using collective wisdom," Decision Support Systems, vol. 59, no. 1, pp. 52-62, 2014.

[11] Z.-H. Hu and Z.-H. Sheng, "A decision support system for public logistics information service management and optimization," Decision Support Systems, vol. 59, no. 1, pp. 219-229, 2014.

[12] J. A. Alalwan, "A taxonomy for decision support capabilities of enterprise content management systems," Journal of High Technology Management Research, vol. 24, no. 1, pp. 10-17, 2013.

[13] S. Damart, L. C. Dias, and V. Mousseau, "Supporting groups in sorting decisions: methodology and use of a multi-criteria aggregation/disaggregation DSS," Decision Support Systems, vol. 43, no. 4, pp. 1464-1475, 2007.

[14] E. Turban, D. Zhou, and J. Ma, "A group decision support approach to evaluating journals," Information \& Management, vol. 42, no. 1, pp. 31-44, 2004.

[15] J. Liebenau and G. Harindranath, "Organizational reconciliation and its implications for organizational decision support systems: a semiotic approach," Decision Support Systems, vol. 33, no. 4, pp. 389-398, 2002.

[16] M. R. Tanniru and H. K. Jain, "Knowledge-based GDSS to support reciprocally interdependent decisions," Decision Support Systems, vol. 5, no. 3, pp. 287-301, 1989.

[17] G. DeSanctis and R. B. Gallupe, "A foundation for the study of group decision support systems," Management Science, vol. 33, no. 5, pp. 589-609, 1987.

[18] G. P. Huber, "Issues in the design of group decision support sytems," MIS Quarterly: Management Information Systems, vol. 8, no. 3, pp. 195-204, 1984.

[19] Y. P. Yang, H. M. Shieh, J. D. Leu, and G. H. Tzeng, "A novel hybrid MCDM model combined with DEMATEL and ANP with applications," International Journal of Operations Research, vol. 5, no. 3, pp. 160-168, 2008.

[20] H. A. Linstone and M. Turoff, The Delphi Method: Techniques and Applications, Addison-Wesley, Reading, Mass, USA, 1975.

[21] L. C. Yang and H. P. Lu, "Applying multiple criteria decision method (MCDM) to evaluate the key factors of a knowledge management system," Information Engineering Letters, vol. 2, no. 3, pp. 28-34, 2012.

[22] E. Fontela and A. Gabus, Current Perceptions of the World Problematique, North Holland, New York, NY, USA, 1976.

[23] T. L. Saaty, Decision Making with Dependence and Feedback: The Analytic Network Process, RWS Publications, Pittsburgh, Pa, USA, 2001.

[24] W. S. Torgerson, "Multidimensional scaling: I. Theory and method," Psychometrika, vol. 17, no. 4, pp. 401-419, 1952.

[25] A. B. Carroll, "Corporate social responsibility: evolution of a definitional construct," Business and Society, vol. 38, no. 3, pp. 268-295, 1999.

[26] A. B. Carroll, "Social issues in management research: experts' views, analysis, and commentary," Business \& Society, vol. 33, no. 1, pp. 5-29, 1994. 


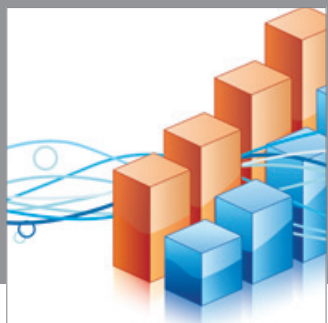

Advances in

Operations Research

mansans

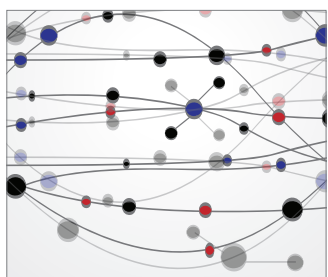

The Scientific World Journal
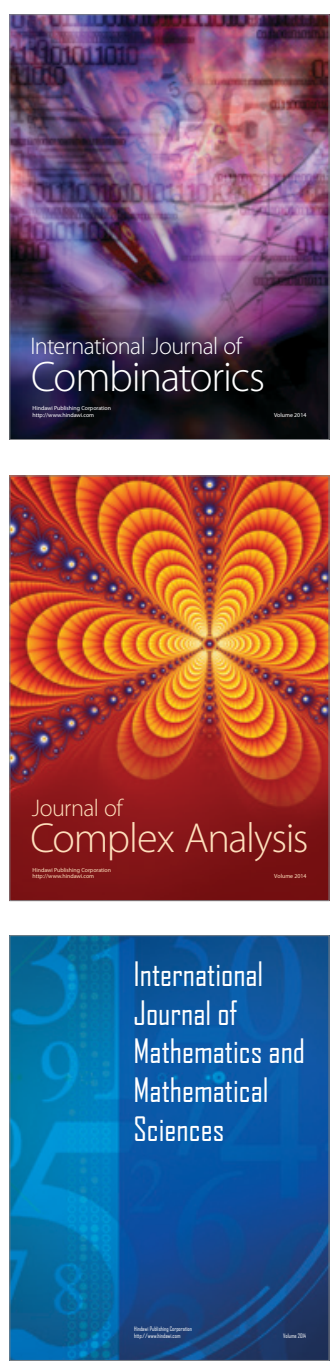
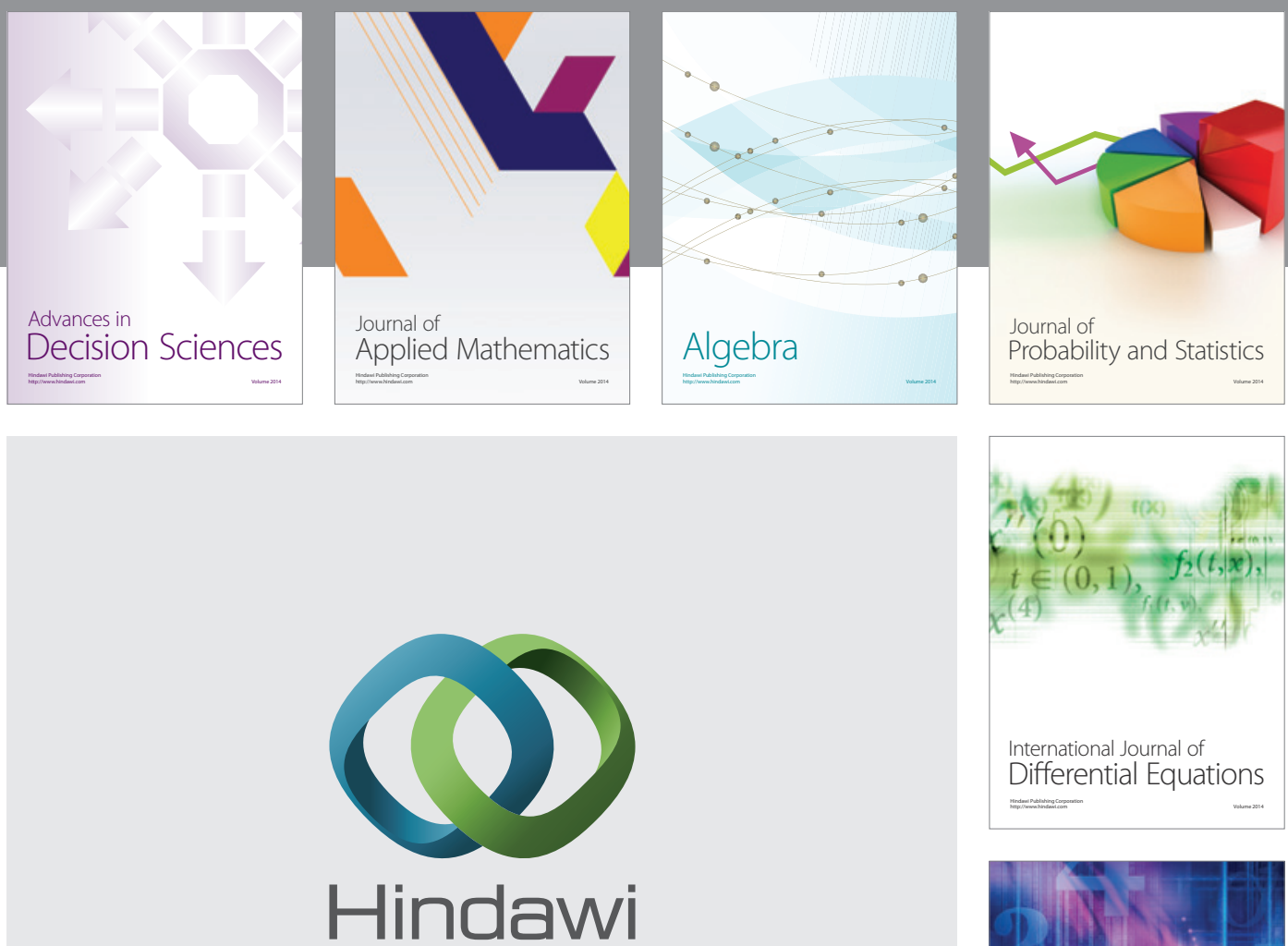

Submit your manuscripts at http://www.hindawi.com
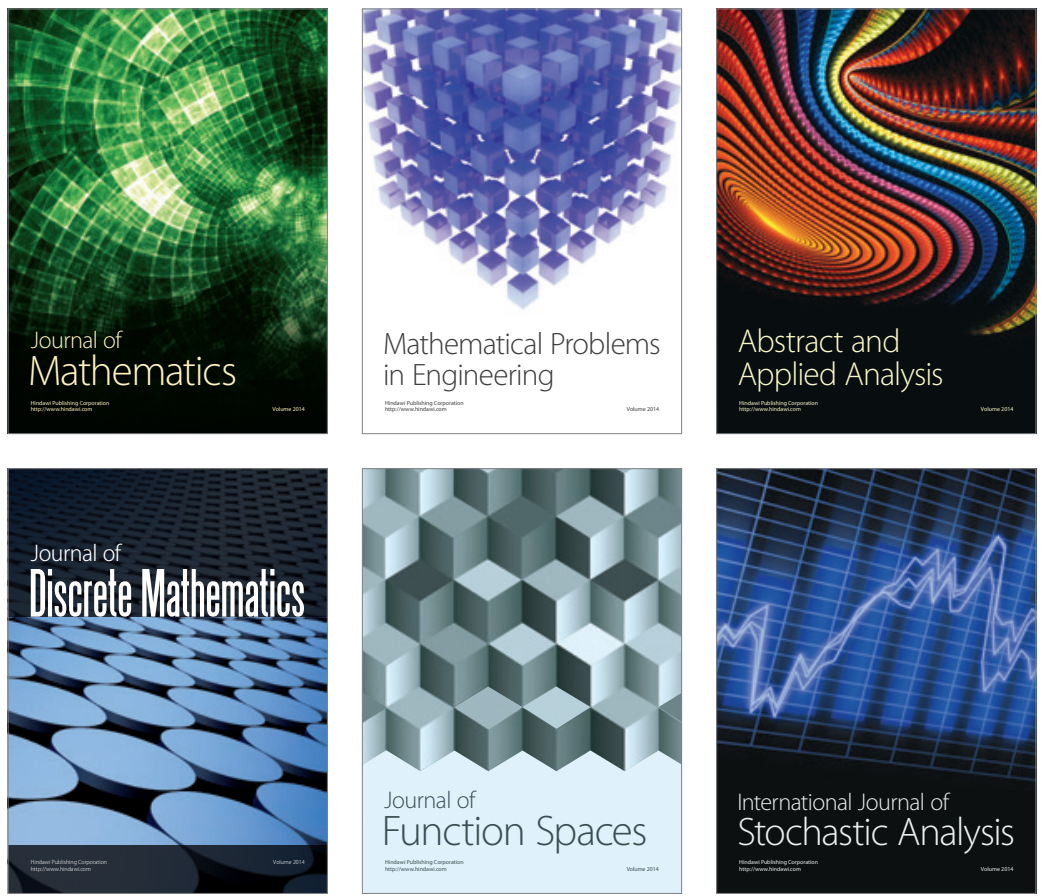

Journal of

Function Spaces

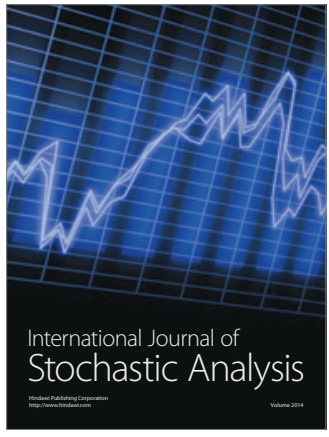

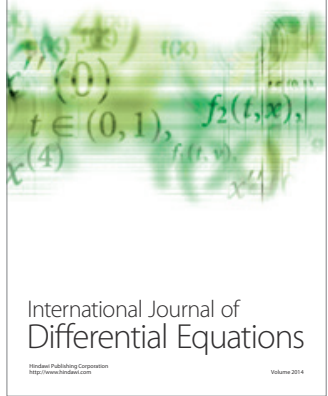
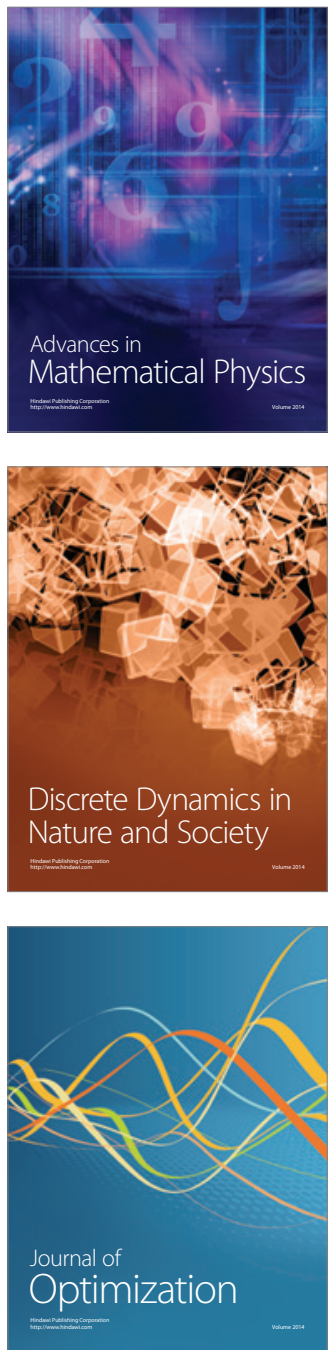